\title{
The effect of post mastectomy radiation therapy on breast reconstruction with and without acellular dermal matrix: a systematic review and meta-analysis protocol
}

\author{
Amy M. Chung ${ }^{*^{*}}$ D, Michael J. Stein ${ }^{2}$, Ammara Ghumman $^{2}$ and Jing Zhang ${ }^{1,2,3}$
}

\begin{abstract}
Background: The widespread implementation of acellular dermal matrix (ADM) has broadened the reconstructive repertoire for alloplastic breast reconstruction. ADM's role in the context of postoperative radiation therapy remains unclear. The present review will evaluate whether ADM reduces complication rates in patients undergoing postmastectomy radiation therapy (PMRT).

Methods: A healthcare librarian assisted in performing a search strategy of electronic databases MEDLINE (via Ovid), EMBASE, and CENTRAL. A combination of the keywords and Medical Subject Headings (MESH) to describe the various commercially available ADMs and terms for radiation therapy will be used. The search strategy will identify patients undergoing postoperative radiation following implant-based breast reconstruction and compare outcomes between those with and without ADM. Extracted data will include patient demographics, intraoperative data, and postoperative complications. Data on patient satisfaction and resource utilization will also be extracted if available. The references of selected works will be reviewed for additional studies meeting study criteria. Only peer-reviewed papers written in English will be included. The study data will be assessed for risk of bias and heterogeneity. Providing that sufficient studies can be identified, a meta-analysis will be performed. This review has been registered with PROSPERO (CRD42017056495).

Conclusions: To date, the short- and long-term performance of ADM in the context of postoperative radiation remains unclear. The objective of the present review will be to critically evaluate the literature with the intention of improving postoperative outcomes in the context of mastectomy and radiation.
\end{abstract}

\section{Background}

Acellular dermal matrix (ADM) is a biointegrative scaffold derived from cadaveric dermis devoid of cellular components. The use of ADM has been transformative in the context of breast reconstruction by providing support and vascularized coverage to the reconstructed breast. They have been shown to lower the risk of capsular contracture, decrease implant migration, increase fill volumes, and improve aesthetic outcomes [1-3], albeit with an increased risk for seroma formation and infection $[4,5]$.

PMRT applied to implant-based breast reconstruction has been associated with a high risk of reconstructive failure and capsular contracture [6]. Complications have been

\footnotetext{
* Correspondence: amy.chung@uottawa.ca

${ }^{1}$ Faculty of Medicine, University of Ottawa, Ottawa, Canada

Full list of author information is available at the end of the article
}

reported to be up to four times higher when ADM is used in the context of radiation [7]. Histologically, radiation therapy results in the inhibition of matrix metalloproteinase- 1 and an increase in the pro-inflammatory cytokines TGF- $\beta$, TNF- $\alpha$, and IFN- $\gamma$ leading to dysregulation of neovascularization and disordered tissue remodeling and integration [3]. In a 2015 histologic study, Mckatyn et al. [8] demonstrated less integration of ADM in patients exposed to PMRT. Biopsies of these patients revealed less vascular penetrance, cellularization, and constructive remodeling of the ADM. Cavallo et al. further demonstrated similar results with preoperative radiation, which resulted in poor cellular and vascular infiltration of the ADM [9].

Others report the contrary. Sbitany et al. [10] demonstrated that ADM was associated with a lower risk of infection and tissue expander/implant exposure than those not 
using it. Similarly, Peled et al. [11] demonstrated that the increased coverage ADM provides lead to a lower rate of expander-implant failure after PMRT compared to partial coverage. Another study evaluating pre-reconstruction radiation found no difference in complication rates with ADM use [12-14].

To date, it is clear that no consensus exists with respect to the use of ADM in the context of one or two stage alloplastic breast reconstruction. The objective of the present study is to compare postoperative outcomes between patients with and without ADM in the context of preoperative and postoperative radiation.

\section{Methods}

\section{Search strategy}

A detailed literature search will be conducted of the electronic databases MEDLINE (via Ovid), EMBASE, and CENTRAL from inception to present. A combination of the keywords and Medical Subject Headings will be used including "Acellular Dermis," "AlloDerm," "Regenerative Tissue Matrix," "DermACELL," "Flex HD," "DermaMatrix," "AlloMax," "SurgiMend," "Radiation Oncology," "Radiotherapy," "Irradiation," "Breast," and "Mammoplasty." The search strategy will be performed by two independent reviewers and compared for consistency (AC and AG). The references of selected works will be assessed by each reviewer to identify additional articles that meet inclusion criteria.

\section{Study criteria}

The types of study to be included are randomized control trials, quasi-randomized studies, cohort studies, case-control, and case series. The gray literature will be searched using the FDA database, ClinicalTrials.gov, and ProQuest Dissertations. Peer-reviewed papers written in English will be included and other languages if translation was provided. Publications involving animal subjects and case-series of less than 10 patients will be excluded. Inclusion criteria consist of female patients 18 years of age or older who underwent alloplastic breast reconstruction and radiation therapy. The primary exposure is ADM use, and studies should compare reconstructions with and without ADM. Specifically, we will not include studies in which all patients were reconstructed with ADM and in which the groups were compared based on radiation status. Table 1 outlines the structure of the study inclusion criteria. The primary outcome of interest is reconstruction failure defined as implant loss. Data on postoperative complications such as infection, seroma, hematoma, dehiscence, capsular contracture, and skin necrosis as defined in Table 2 will be collected and analyzed separately. Lastly, patient-reported outcomes will be included when available using the BREAST-Q questionnaire.
Table 1 PICO format of studies for inclusion in the structured literature review

\begin{tabular}{ll}
\hline Population & $\begin{array}{l}\text { Women }>18 \text { years of age undergoing implant-based } \\
\text { breast reconstruction AND radiation therapy }\end{array}$ \\
Intervention & ADM use in reconstructive surgeries \\
Comparison & Reconstructions performed without ADM \\
Outcome & Reconstruction failure \\
\hline
\end{tabular}

\section{Screening}

Search results will be entered into the latest version of EndNote (Clarivate Analytics), and duplicates will be removed. The search results will be screened by two independent reviewers (AC and $\mathrm{AG}$ ) in a two-stage process, first, based the title and abstract, and second as a review of the full article. Disagreements will be resolved by consulting a third, more senior reviewer. The justification for exclusion from the review will be documented.

\section{Data extraction}

This literature review will be conducted in accordance with the PRISMA-P statement to ensure comprehensiveness and transparency [15]. Data will be extracted using predesigned forms. In the event of missing data, the corresponding author of the study will be contacted (Additional files 1 and 2).

\section{Data analysis}

The program Review Manager (RevMan) 5.1 will be used for data analysis and to tabulate the findings. The unit of analysis will be by patient as opposed to by breast. For studies reporting outcomes by breast, the data will be converted to reflect the complications by patient where possible. Breast reconstruction reflects a heterogenous population based on whether it was immediate or delayed and one or two stages. The analysis will seek to group studies with the same reconstructive timing and stages together. The primary outcome will be reconstruction failure. Data will be analyzed and grouped based on study design. The

Table 2 Definition of postoperative complications

\begin{tabular}{|c|c|}
\hline Complication & Definition \\
\hline $\begin{array}{l}\text { Superficial surgical site } \\
\text { infection (SSI) }\end{array}$ & $\begin{array}{l}\text { Infection at the surgical site requiring } \\
\text { oral antibiotics }\end{array}$ \\
\hline $\begin{array}{l}\text { Deep superficial site } \\
\text { infection (SSI) }\end{array}$ & $\begin{array}{l}\text { Infection at the surgical site requiring } \\
\text { intravenous antibiotics }\end{array}$ \\
\hline Seroma & A collection of clear fluid in the breast \\
\hline Hematoma & A collection of blood in the breast \\
\hline Dehiscence & $\begin{array}{l}\text { Opening of the wound along the } \\
\text { surgical incision }\end{array}$ \\
\hline $\begin{array}{l}\text { Capsular } \\
\text { contracture }\end{array}$ & $\begin{array}{l}\text { The formation of disruptive scar formation } \\
\text { surrounding the implant capsule } \\
\text { of Baker Grade III or IV }\end{array}$ \\
\hline Skin necrosis & $\begin{array}{l}\text { Cell death of the mastectomy flap or skin } \\
\text { surrounding the surgical site }\end{array}$ \\
\hline
\end{tabular}


study outcomes will be reported as proportions and analyzed using odds ratios (OR). We will evaluate reconstruction failure and specific complications where applicable. Data will be summarized using Forest plots. The $I^{2}$ test will be used to evaluate statistical heterogeneity [16]. If there is low-moderate heterogeneity detected $\left(I^{2}<50 \%\right)$, we will perform a fixed-effects meta-analysis [17]. The Mantel-Haenszel method will be used to compute a weighted odds ratio. If there is substantial heterogeneity $\left(I^{2}>50 \%\right)$ or clinical heterogeneity, we will attempt to determine explanations for this and will apply a random-effects model for analysis [18] A sensitivity analysis will be performed by removing trials that are outliers, in order to determine the degree to which the overall outcomes were influenced by contributions to the heterogeneity. Given the multitude of reconstructive options available to breast cancer patients, we anticipate considerable heterogeneity among the studies.

Publication bias will be assessed graphically using a funnel plot where the treatment effect is plotted against a measure of study size [19]. Individual, randomized studies will be assessed by the reviewers using the Cochrane Risk of Bias tool [24] [20]. Non-randomized studies will be assessed using the Risk Of Bias In Non-randomized Studies-of Interventions (ROBINS-I) Tool [21]. Each outcome will be assigned a GRADE score. The ability to perform a meta-analysis will depend on the number of articles identified from the search.

\section{Limitations}

The present review is limited by the heterogeneity in the literature given the variation in radiation timing and multitude of reconstructive options available to women. Furthermore, as our search was limited to radiated patients it is possible to miss data if the data on $\mathrm{ADM}$ and radiation is part of a subanalysis of a larger study.

\section{Discussion}

Since its introduction in 1994, it has become clear that ADM has made a significant positive impact on patients undergoing alloplastic breast reconstruction. Despite this, the full scope of its performance, particularly in the context of radiation, remains unclear. The present review hopes to determine the effect of ADM on outcomes in patients who underwent immediate breast reconstruction and radiation therapy.

\section{Conclusions}

The present review will help inform guidelines regarding the use of ADM in patients receiving preoperative and postoperative radiation.

\section{Additional files}

Additional file 1: Search Strategy for electronic database search of MEDLINE (via Ovid), EMBASE and CENTRAL. (DOCX $15 \mathrm{~kb}$ )

Additional file 2: PRISMA-P Checklist for study. (DOCX $9 \mathrm{~kb}$ )

\section{Abbreviations}

ADM: Acellular dermal matrix; PMRT: Post mastectomy radiation therapy; PRISMA-P: Preferred Reporting Items for Systematic Reviews and MetaAnalysis Protocol

\section{Acknowledgements}

The authors would like to thank Risa Shorr, Librarian at The Ottawa Hospital, for her assistance with designing the search strategy.

\section{Funding}

None.

Availability of data and materials Not applicable.

\section{Authors' contributions}

JZ conceived the study concept and is the guarantor of the study data. AC with the assistance of Risa Shorr developed the search strategy. AC, AG, MS, and JZ contributed to selecting study inclusion/exclusion criteria and study design. AC and $A G$ developed analysis and meta-analysis design. AC and AG will review the papers for inclusion in the review with disagreements resolved by MS and JZ. All authors contributed to the writing and review of the final manuscript. All authors read and approved the final manuscript.

Ethics approval and consent to participate

Not applicable.

\section{Competing interests}

The authors declare that they have no competing interests.

\section{Publisher's Note}

Springer Nature remains neutral with regard to jurisdictional claims in published maps and institutional affiliations.

\section{Author details}

${ }^{1}$ Faculty of Medicine, University of Ottawa, Ottawa, Canada. ${ }^{2}$ Division of Plastic and Reconstructive Surgery, Univeristy of Ottawa, Ottawa, Ontario, Canada. ${ }^{3}$ Department of Surgery, The Ottawa Hospital - Civic Campus, 1053 Carling Avenue Box 213, Ottawa, ON K1Y 4E9, Canada.

Received: 29 November 2017 Accepted: 22 January 2019 Published online: 21 February 2019

References

1. Macadam SA, Lennox PA. Acellular dermal matrices: use in reconstructive and aesthetic breast surgery. Can J Plast Surg. 2012;20(2):75-89.

2. Ho G, Nguyen TJ, Shahabi A, Hwang BH, Chan LS, Wong AK. A systematic review and meta-analysis of complications associated with acellular dermal matrix-assisted breast reconstruction. Ann Plast Surg. 2012;68(4):346-56.

3. Salzberg CA. Nonexpansive immediate breast reconstruction using human acellular tissue matrix graft (Alloderm). Ann Plast Surg. 2006;57(1):1-5.

4. Chun YS, Verma K, Rosen H, Lipsitz S, Morris D, Kenney P, Eriksson E. Implant-based breast reconstruction using acellular dermal matrix and the risk of postoperative complications. Plast Reconstr Surg. 2010;125(2):429-36.

5. Parks JW, Hammond SE, Walsh WA, Adams RL, Chandler RG, Luce EA. Human acellular dermis versus no acellular dermis in tissue expansion breast reconstruction. Plast Reconstr Surg. 2012;130(4):739-46.

6. Ricci JA, Epstein S, Momoh AO, Lin SJ, Singhal D, Lee BT. A meta-analysis of implant-based breast reconstruction and timing of adjuvant radiation therapy. J Surg Res. 2017:218:108-16.

7. Mitchell RE. Porcine cellular dermis-assisted breast reconstruction: influence of adjuvant radiotherapy on complications and outcomes. Plastic and Reconstructive Surgery Global Open. 2013;1(8):e77. 
8. Myckatyn TM, Cavallo JA, Sharma K, Gangopadhyay N, Dudas JR, Roma AA Baalman S, Tenenbaum MM, Matthews BD, Deeken CR. The impact of chemotherapy and radiation on the remodeling of acellular dermal matrices in staged, prosthetic breast reconstruction. Plast Reconstr Surg. 2015;135(1):43e.

9. Cavallo JA, Gangopadhyay N, Dudas J, Roma AA, Jasielec MS, Baty J, Baalman S, Frisella MM, Tenenbaum MM, Myckatyn TM, Matthews BD. Remodeling characteristics and collagen distributions of biologic scaffold materials biopsied from postmastectomy breast reconstruction sites. Ann Plast Surg. 2015;75(1):74.

10. Sbitany H, Wang F, Peled AW, Lentz R, Alvarado M, Ewing CA, Esserman L, Fowble B, Foster RD. Immediate implant-based breast reconstruction following total skin-sparing mastectomy: defining the risk of preoperative and postoperative radiation therapy for surgical outcomes. Plast Reconstr Surg. 2014;134(3):396-404.

11. Peled AW, Foster RD, Esserman $\sqcup$, Park CC, Hwang ES, Fowble B. Increasing the time to expander-implant exchange after postmastectomy radiation therapy reduces expander-implant failure. Plast Reconstr Surg. 2012;130(3):503-9.

12. Ibrahim AM, Shuster M, Koolen PG, Kim K, Taghinia AH, Sinno HH, Lee BT, Lin SJ. Analysis of the National Surgical Quality Improvement Program database in 19,100 patients undergoing implant-based breast reconstruction: complication rates with acellular dermal matrix. Plast Reconstr Surg. 2013;132(5):1057-66.

13. Weichman KE, Cemal Y, Albornoz CR, McCarthy CM, Pusic AL, Mehrara BJ, Disa JJ. Unilateral preoperative chest wall irradiation in bilateral tissue expander breast reconstruction with acellular dermal matrix: a prospective outcomes analysis. Plast Reconstr Surg. 2013:131(5):921-7.

14. Ibrahim AM, Koolen PG, Ashraf AA, Kim K, Mureau MA, Lee BT, Lin SJ. Acellular dermal matrix in reconstructive breast surgery: survey of current practice among plastic surgeons. Plastic and Reconstructive Surgery Global Open. 2015;3(4).

15. Moher D, Shamseer L, Clarke M, Ghersi D, Liberati A, Petticrew M, Shekelle P, Stewart LA. PRISMA-P Group. Preferred reporting items for systematic review and meta-analysis protocols (PRISMA-P) 2015 statement. Syst Rev. 2015;:1.

16. Higgins J, Thompson SG. Quantifying heterogeneity in a meta-analysis. Stat Med. 2002;21(11):1539-58.

17. DeMets DL. Methods for combining randomized clinical trials: strengths and limitations. Stat Med. 1987;6(3):341-8.

18. DerSimonian R, Laird N. Meta-analysis in clinical trials. Control Clin Trials. 1986;7(3):177-88.

19. Light RJ, Pillemer DB. Quantitative procedures. The science of reviewing research; 1984.

20. Higgins JP, Green S. Cochrane Handbook for Systematic Reviews of Interventions Version5.1.0 [updated March 2011]. The Cochrane Collaboration. 2011. Available from http://handbook.cochrane.org.

21. Sterne JA, Hernán MA, Reeves BC, Savović J, Berkman ND, Viswanathan M, Henry D, Altman DG, Ansari MT, Boutron I, Carpenter JR. ROBINS-I: a tool for assessing risk of bias in non-randomised studies of interventions. BMJ. 2016; 355:i4919.

Ready to submit your research? Choose BMC and benefit from:

- fast, convenient online submission

- thorough peer review by experienced researchers in your field

- rapid publication on acceptance

- support for research data, including large and complex data types

- gold Open Access which fosters wider collaboration and increased citations

- maximum visibility for your research: over $100 \mathrm{M}$ website views per year

At BMC, research is always in progress.

Learn more biomedcentral.com/submissions 